RECyT

Año 21 / № 32 / 2019 / 56-63

\title{
Extracción de pectina a partir de albedo de limón con una Poligalacturonasa de Wickerhamomyces Anomalus
}

\section{Extraction of pectin from lemon albedo with a polygalacturonase of Wickerhamomyces Anomalus}

\author{
Silvana A.Maidana1, ${ }^{1}$, Claudia L. Danovich ${ }^{1}$, Emilce R. Zubreski ${ }^{1}$, María A. Martos ${ }^{1}$ \\ 1- Facultad de Ciencias Exactas, Químicas y Naturales. Universidad Nacional de \\ Misiones (UNaM). Ruta 12, km 7,5, Miguel Lanús, Misiones, Argentina. \\ * E-mail: silvana.a.maidana@gmail.com
}

\section{Resumen}

\begin{abstract}
El objetivo del presente trabajo fue evaluar el efecto de diferentes factores en la extracción de pectina a partir de albedo de limón, mediante el extracto enzimático con actividad poligalacturonasa de Wickerhamomyces anomalus (WA cepa 110), una levadura autóctona de la provincia de Misiones, Argentina.

El proceso de extracción enzimática de pectina se realizó en frascos Erlenmeyers conteniendo albedo de limón, buffer y el extracto enzimático crudo de WA cepa 110, con agitación (pH 5,0). Los factores evaluados fueron: relación sólido/líquido, temperatura, tiempo y actividad enzimática. El material polimérico se precipitó con etanol y el peso seco del gel obtenido se denominó material insoluble en etanol (MIE).

Se obtuvieron rendimientos de MIE de $35,93 \pm 0,67 \%(p / p)$, con una relación sólido/líquido de 1/50, $12,5 \mathrm{~mL}$ del EE (actividad PGasa en el medio de reacción: $4,28 \mathrm{UE} / \mathrm{mL}$ ), $40^{\circ} \mathrm{C}, 4 \mathrm{~h}$ y pH 5,0. Este valor fue superior al obtenido utilizando el método químico, lo cual confirma la bondad del proceso enzimático utilizado.
\end{abstract}

Palabras clave: Extracción; Wickerhamomyces anomalus; Poligalacturonasa; Pectina de citrus; Albedo de limón.

\section{Abstract}

The objective of the present work was to evaluate the effect of different factors on the extraction of pectin from lemon albedo, using the enzymatic extract with polygalacturonase activity of Wickerhamomyces anomalus (WA strain 110), a native yeast from the Province of Misiones, Argentina.

Pectin extraction process was carried out in Erlenmeyer flasks containing lemon albedo, buffer and the crude enzymatic extract of WA strain 110, with agitation ( $\mathrm{pH}$ 5.0). Factors studied were: solid-liquid ratio, temperature, time and enzyme activity. The soluble polymeric material was precipitated with ethanol and the weight of the dried gel obtained was named as ethanol insoluble material (EIM).

It was obtained a yield of MIE of $35.93 \pm 0.67 \%(\mathrm{~W} / \mathrm{w})$, with a solid / liquid ratio of 1/50, $12.5 \mathrm{~mL}$ of EE (PGase activity in the reaction medium: $4.28 \mathrm{UE} / \mathrm{mL}), 40^{\circ} \mathrm{C}, 4 \mathrm{~h}$, and pH 5.0. This value was higher than that obtained using the chemical method, which confirms the goodness of the enzymatic process used.

Keywords: Extraction; Wickerhamomyces anomalus; Polygalacturonase; Citrus pectin; Lemon albedo

\section{Introducción}

Las pectinas constituyen un grupo heterogéneo de polisacáridos ácidos de origen vegetal con propiedades de gelificación, estabilización de emulsiones y aporte de fibra nutricional, siendo muy utilizadas en la industria alimenticia para la elaboración de bebidas, mermeladas, productos lácteos, etc. Su precursor es la protopectina, definida como la sustancia péctica insoluble en agua, que origina pectina soluble por despolimerización parcial [1,2].

Argentina importa toda la pectina consumida en forma de polvo listo para solubilizar, lo cual posee un alto costo para las industrias locales [3].
Para la producción de pectina, se utilizan algunos subproductos de las industrias de jugos de frutas, principalmente cáscaras de cítricos y orujo de manzana. A escala industrial, la pectina se extrae mediante procesos físico-químicos, basados en la hidrólisis ácida de tejidos vegetales. Estos procesos requieren altas temperaturas, lo que demanda un elevado gasto energético además de generar desechos peligrosos para el medio ambiente [4, 5].

Desde hace algunos años se han reportado diversos trabajos relacionados con el uso de técnicas enzimáticas para la extracción de pectina, las que emplean condiciones de extracción mucho más suaves que los métodos químicos. Sin embargo, son escasos los estudios realizados que 
evalúan la optimización de las condiciones de operación de dichos procesos [2, $6-8]$.

Los procedimientos enzimáticos para la extracción de pectina, utilizan enzimas de origen microbiano denominadas enzimas solubilizadoras de pectina o protopectinasas (PPasas).

Las PPasas tienen la capacidad de hidrolizar restringidamente la protopectina presente en los tejidos vegetales, liberando pectina soluble y conduciendo al ablandamiento del tejido vegetal (proceso de maceración) [2, 9 - 15]. La actividad PPasa se considera como una característica particular de algunas poligalacturonasas (PGasas), que tienen una afinidad particularmente alta por sustratos insolubles [16]. La primer PPasa reportada se encontró en el sobrenadante de un cultivo de Geotrichum klebahnii ATCC 42397, que fue identificada como una endo-poligalacturonasa (endo-PGasa) [10].

Wickerhamomyces anomalus es una levadura que, al crecer en medio líquido, secreta una única enzima con actividad PGasa. La enzima fue purificada, caracterizada e identificada como una endo-PGasa (EC 3.2.1.15), con un peso molecular de $43 \mathrm{kDa}$ (determinado por SDS-PAGE). La misma exhibió una actividad máxima a $\mathrm{pH} 4,2$, permaneciendo estable en un $86 \%$ de la actividad enzimática máxima en un rango de $\mathrm{pH}$ entre 3,5 a 6,0 y hasta los $50^{\circ} \mathrm{C}$ durante $10 \mathrm{~h}[17,18]$. En estudios previos se determinó que esta enzima posee, a diferencia de otras PGasas, actividad PPasa, y fue capaz de macerar tejidos vegetales [19].

El objetivo del presente trabajo fue evaluar el efecto de diferentes factores en la extracción de pectina a partir de albedo de limón, mediante el extracto enzimático con actividad poligalacturonasa de Wickerhamomyces anomalus (WA cepa 110).

\section{Materiales y Métodos}

\section{Microorganismo, mantenimiento y conservación}

En el presente trabajo se utilizó una levadura autóctona de la Provincia de Misiones, Argentina, aislada a partir de cáscaras de frutas cítricas en el laboratorio de Microbiología de Alimentos y Biotecnología "Dr. Fernando O. Benassi”, de la Facultad de Ciencias Exactas, Químicas y Naturales, UNaM, Misiones, Argentina. Esta levadura fue identificada previamente por métodos moleculares como Wickerhamomyces anomalus en el Instituto Nacional de Tecnología Agropecuaria (INTA), Centro Regional Mendoza, San Juan [20]. La cepa (Wa cepa 110) fue mantenida en estrías de un medio de mantenimiento, a $5^{\circ} \mathrm{C}$, hasta 2 meses y conservada por liofilización.

Para la conservación por liofilización, se realizó una suspensión de células, a partir de estrías jóvenes ( 24 h) de la levadura, en una solución crioprotectora de leche descremada (Nestlé) al 10\% (p/v) e inositol trifosfato (Anedra) al
$5 \%(\mathrm{p} / \mathrm{v})$. La suspensión fue congelada a $-80^{\circ} \mathrm{C}$ y posteriormente liofilizada. Al final del proceso, las ampollas con el liofilizado fueron selladas y conservadas a $5^{\circ} \mathrm{C}$. Cuando fue necesario, una ampolla que contenía la levadura fue recuperada luego de re-hidratación con agua estéril, seguida de cultivo en estrías de medio de mantenimiento.

\section{Medios de cultivos}

a) Medio de mantenimiento $(Y M-\mathrm{g} / \mathrm{L})$ : extracto de levadura (Sigma Chemical Co., St. Louis, Mo, EEUU), 5; Triptona (Difco-Becton Dickinson \& Co., Sparks, MD, EEUU), 5; Glucosa (Britania, Buenos Aires, Argentina), 10; Agar (Britania), 15; pH 5,0.

b) Medio de fermentación (g/L): glucosa (Britania), 10; pectina de citrus (Parafarm, Buenos Aires, Argentina), 5; $\left(\mathrm{NH}_{4}\right)_{2} \mathrm{SO}_{4}, 3 ; \mathrm{KH}_{2} \mathrm{PO}_{4}, 1 ; \mathrm{MgSO}_{4}, 0,5 ; \mathrm{CaCl}_{2}, 0,1$; solución de vitaminas $(1000 \times), 1 \mathrm{~mL} / \mathrm{L}$; solución de aminoácidos $(100 \times), 10 \mathrm{~mL} / \mathrm{L}$; solución de microelementos $(1000 \times), 1 \mathrm{~mL} / \mathrm{L} ; \mathrm{pH} 5,0$ [21].

Solución $(1000 \times)$ de vitaminas (Sigma) $(\mu \mathrm{g} / \mathrm{L})$ : biotina, 2; pantotenato de Ca, 400; ácido fólico, 2; inositol, 2000; niacina, 400; ácido $p$-aminobenzoico, 200; piridoxina, 400; riboflavina, 200; tiamina, 400.

Solución $(100 \times)$ de aminoácidos (Sigma) $(\mathrm{mg} / \mathrm{L})$ : histidina, 10; metionina, 20 y triptófano, 20.

Solución de microelementos $1000 \times(\mu \mathrm{g} / \mathrm{L})$ : $\mathrm{CuSO}_{4} \cdot 5 \mathrm{H}_{2} \mathrm{O}, 40 ; \mathrm{FeCl}_{3} \cdot 6 \mathrm{H}_{2} \mathrm{O} ; 200 ; \mathrm{MnSO}_{4} \cdot \mathrm{H}_{2} \mathrm{O}, 400$; $\mathrm{NaMoO}_{4} \cdot 2 \mathrm{H}_{2} \mathrm{O}, 200 ; \mathrm{ZnSO}_{4} \cdot 7 \mathrm{H}_{2} \mathrm{O}, 400$.

Todos los componentes del medio fueron autoclavados $\left(121^{\circ} \mathrm{C}, 15 \mathrm{~min}\right)$, excepto las vitaminas, que se esterilizaron por separado a través de un papel de filtro celulósico de 0,22 $\mu \mathrm{m}$ de diámetro de poro (Sartorius Stedim Biotech, Alemania).

\section{Producción del extracto enzimático}

Precultivos: se inocularon tres frascos Erlenmeyers de $500 \mathrm{~mL}$ que contenían $95 \mathrm{~mL}$ del medio de fermentación con $5 \mathrm{~mL}$ de inóculo $\left(\mathrm{DO}_{620}=0,96\right)$ provenientes de un cultivo joven (24 h) de Wa cepa 110, en medio de mantenimiento. Los mismos se incubaron a $30^{\circ} \mathrm{C}$ con agitación (180 rpm), durante $20 \mathrm{~h}$. Al cabo de este tiempo, las células contenidas en los cultivos $(300 \mathrm{~mL})$ se cosecharon por centrifugación, el sobrenadante se descartó y las células se resuspendieron en $100 \mathrm{~mL}$ de agua destilada estéril $(300 \mathrm{~mL})$.

Fermentación: para el proceso fermentativo se utilizó un biorreactor de 5 L de capacidad (New Brunwick Scientific Co., Edison, EEUU) que contenía 2,7 L de medio de fermentación, el que fue inoculado con la suspensión de levadura de los precultivos. El cultivo se realizó a $30^{\circ} \mathrm{C}$, hasta $10 \mathrm{~h}$, con agitación (500 rpm) y suministrándole aire estéril a un caudal de $2,82 \mathrm{~L} / \mathrm{min}$. Al finalizar el cultivo, el fermento fue centrifugado para remover las células de levaduras. El sobrenadante crudo libre de células fue denominado extracto 
enzimático (EE) y se mantuvo a $-18^{\circ} \mathrm{C}$ hasta su utilización como fuente de enzima extracelular [17, 21].

La actividad PGasa del EE se midió por determinación de los grupos reductores liberados, a partir de una solución de ácido poligalacturónico (Sigma), en una solución tampón de acetato sódico/ácido acético (BAc, 0,2 M, pH $5,0)$, mediante el método de Somogy-Nelson. La reacción se llevó a cabo a $37^{\circ} \mathrm{C}$ durante 10 minutos. Se realizó una curva de calibración con ácido galacturónico (AG, Sigma) como estándar. Una unidad PGasa se definió como la cantidad de enzima que liberó $1 \mu \mathrm{mol}$ de AG por minuto bajo las condiciones de ensayo [10, 22, 23].

\section{Tratamiento de la materia prima}

Para la obtención de la materia prima, se seleccionaron limones frescos de la variedad Eureka, adquiridos en un local comercial en la ciudad de Posadas, Misiones, Argentina. Los frutos fueron lavados y posteriormente se extrajo mecánicamente el mesocarpio o albedo. El albedo fue tratado con calor $\left(15 \mathrm{~min}\right.$, a $\left.100^{\circ} \mathrm{C}\right)$, simulando un proceso de escaldado, para inactivar enzimas endógenas, principalmente pectinesterasas (PE), las cuales desmetoxilan y despolimerizan las pectinas [9]. Posteriormente el material vegetal fue lavado, para eliminar sustancias pécticas solubles, secado, molido y tamizado (45 mesh), denominando a este material como albedo tamizado (AT). El producto deshidratado se almacenó en frascos de polietileno al abrigo de la luz y de la humedad [24].

\section{Extracción enzimática de pectina}

El proceso de extracción se realizó en frascos Erlenmeyers con una relación sólido/líquido (S/L) 1/40, constituida por $1 \mathrm{~g}$ del material vegetal, $20 \mathrm{~mL}$ de buffer acetato de sodio/ácido acético $(0,2 \mathrm{M}, \mathrm{pH} 5,0)$ y $20 \mathrm{~mL}$ del EE $(19,57 \pm 0,55 \mathrm{UE} / \mathrm{mL})$, a $30^{\circ} \mathrm{C}$, en baño termostatizado rotatorio $(150 \mathrm{rpm})$ por $6 \mathrm{~h}$. Luego de la incubación, la totalidad de cada Erlenmeyer se centrifugó a $2350 \times$ g, durante 10 min [9]. El material polimérico del sobrenadante se precipitó con 2 volúmenes de etanol frío al 96\% (v/v) y se mantuvo a $5^{\circ} \mathrm{C}$ durante $2 \mathrm{~h}$. El gel obtenido fue lavado con etanol al $70 \%(\mathrm{v} / \mathrm{v})$, centrifugado a $2350 \times g$, durante $15 \mathrm{~min}$, descartándose el sobrenadante y secado en estufa a $45^{\circ} \mathrm{C}$ hasta peso constante. El material polimérico obtenido fue denominado material insoluble en etanol (MIE). El rendimiento en la extracción de pectina se reporta como $\mathrm{g}$ de MIE por cada $100 \mathrm{~g}$ de albedo seco [2, 25-28]. En todos los casos, se realizaron blancos con la enzima inactivada.

\section{Efecto de diferentes factores sobre el proceso de solubilización de pectina}

En la presente etapa del trabajo se estudió el efecto de diferentes factores sobre la extracción de pectina a partir de albedo de limón, con el EE de Wa cepa 110.Los estudios se realizaron mediante la metodología de "un factor por vez", mientras se mantenían constantes los demás factores[29, 30]. En todos los casos, se siguió el protocolo de extracción descripto anteriormente.

Efecto de la relación sólido/líquido: se evaluó el rendimiento de extracción de pectina, empleando diferentes relaciones $\mathrm{S} / \mathrm{L}(\% \mathrm{p} / \mathrm{v}): 1: 20,1: 40,1: 50$ y 1:60, manteniendo constante la actividad de la enzima en la mezcla de reacción.

Efecto de la temperatura y el tiempo: considerando que en estudios previos se demostró que la enzima permanece estable hasta $\operatorname{los} 50^{\circ} \mathrm{C}$, durante $10 \mathrm{~h}$ de incubación [18], se evaluó la solubilización enzimática de pectina a diferentes temperaturas y hasta $\operatorname{los} 50^{\circ} \mathrm{C}$, en función del tiempo de reacción.

Influencia de la actividad enzimática: se estudió la posibilidad de utilizar menor concentración del EE, a fin de disminuir los costos del proceso. Para ello se realizó la solubilización de pectina utilizando diferentes volúmenes del EE, pero manteniendo la misma relación $\mathrm{S} / \mathrm{L}$.

Análisis estadístico: Las experiencias se realizaron por triplicado y se tomaron para los cálculos los valores promedios. Los resultados se analizaron mediante ANOVA simple, aplicando el programa estadístico Stat Graphics [31].

\section{Extracción por Método Químico}

Para la extracción química de pectina se suspendieron 2,5 g de albedo de limón en $60 \mathrm{~mL}$ de agua destilada, se ajustó el pH a 2,0 con ácido clorhídrico $1 \mathrm{~N}$, la mezcla se calentó a $90^{\circ} \mathrm{C}$ en baño de agua termostatizado, durante 60 min, agitando a intervalos frecuentes. La mezcla resultante se enfrió, centrifugó y el material polimérico del sobrenadante se precipitó con etanol y se prosiguió según se describió anteriormente [32 - 34].

\section{Determinaciones analíticas}

Contenido de ácido galacturónico $(A G)$ en el MIE: se determinó por el método colorimétrico descripto por Melton y Smith (2001) [35]. En este procedimiento se emplea el reactivo $m$-hidroxidifenilo (mHDP), en presencia de ácido sulfámico $\left(\mathrm{H}_{3} \mathrm{NSO}_{3}\right)$ para evitar la interferencia por azúcares neutros. La absorbancia de los tubos se midió en un espectrofotómetro (Beckman DU 640, a $37^{\circ} \mathrm{C}$ ) a $525 \mathrm{~nm}$. El contenido de AG indica la pureza de la pectina extraída y no debe ser menor al 65\% [36].

Grado de esterificación (GE): el GE de una pectina se define como el porcentaje de grupos carboxilos esterificados con metanol (número de moles de metanol por 100 moles de AG). La determinación del GE de la pectina obtenida se efectuó empleando el método titulométrico [2, 37]. 


\section{Resultados y Discusión}

La extracción enzimática de polisacáridos de tejidos vegetales, es un proceso de catálisis heterogénea, donde una enzima soluble actúa sobre un sustrato insoluble. Diferentes factores influyen en este tipo de reacciones. En base a la bibliografía, en el presente trabajo se estudió el efecto de la relación sólido/líquido, concentración de enzima, temperatura y tiempo de hidrólisis, sobre la extracción de pectina a partir de albedo de limón, con el EE de Wa cepa $110[2,38]$.

Los estudios se realizaron mediante la metodología de "un factor por vez", mientras se mantenían constantes los demás factores, a fin de evaluar el efecto de ese único nutriente sobre el proceso de extracción de pectina $[18$, $29,30]$.

\section{Efecto de la relación sólido/líquido}

En la Tabla 1, se presenta el análisis de rangos múltiples correspondiente al efecto de la relación $\mathrm{S} / \mathrm{L}$ sobre la capacidad de solubilización de pectina, por el EE de Wa cepa 110 y en la Figura 1, el gráfico de comparación de medias. Los resultados se presentan como porcentaje del rendimiento de pectina obtenido bajo las siguientes condiciones de reacción no optimizadas: relación $\mathrm{S} / \mathrm{L} 1 / 40(\mathrm{p} / \mathrm{p}), 30^{\circ} \mathrm{C}$, $6 \mathrm{~h}$ y $20 \mathrm{~mL}$ EE, el cual corresponde a un rendimiento del $100 \%$.

Tabla 1:Análisis de rangos múltiples para el efecto de la relación S/L sobre el porcentaje de extracción de pectina.

\begin{tabular}{|c|c|c|c|}
\hline Relación & Cantidad & Media & Grupos homogéneos \\
\hline $1 / 20$ & 3 & 67,155 & $X$ \\
\hline $1 / 40$ & 3 & 100,000 & $X$ \\
\hline $1 / 50$ & 3 & 107,506 & $X$ \\
\hline $1 / 60$ & 3 & 113,230 & \\
\hline Contraste & & Diferencias & \\
\hline $1 / 20-1 / 40$ & & ${ }^{*}-12,1067$ & \\
\hline $1 / 20-1 / 50$ & & ${ }^{*}-14,8733$ & \\
\hline $1 / 20-1 / 60$ & & ${ }^{*}-16,9833$ & \\
\hline $1 / 40-1 / 50$ & & ${ }^{*} 2,76667$ & \\
\hline $1 / 40-1 / 60$ & & $*-4,87667$ & \\
\hline $1 / 50-1 / 60$ & & $-2,11$ & \\
\hline * denota diferencia significativa $(p<0,05)$. & \\
\hline
\end{tabular}

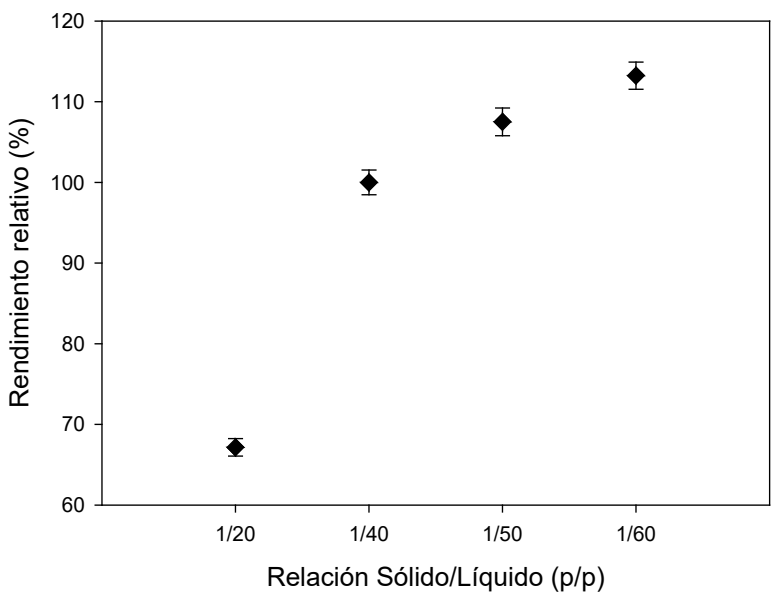

Figura 1: Efecto de la relación S/L en el rendimiento de extracción de pectina con el extracto enzimático de Wa cepa 110. Condiciones de extracción: $30^{\circ} \mathrm{C}, 6$ h, $20 \mathrm{~mL}$ EE.

$\mathrm{El}$ análisis de varianza determinó que la relación $\mathrm{S} / \mathrm{L}$ influyó significativamente $(p<0,05)$ en el proceso de extracción de pectina. El análisis de rangos múltiples (Tabla 1), indicó que la diferencia se observó entre las relaciones $1 / 20,1 / 40$ y $1 / 50$, no habiendo diferencia entre las relaciones 1/50 y 1/60. En la Figura 1 se observa que los mayores rendimientos se obtuvieron con una relación $\mathrm{S} / \mathrm{L}$ de $1 / 50$ o $1 / 60$, los cuales fueron superiores respecto al rendimiento obtenido bajo condiciones no optimizadas. En base a los resultados obtenidos en esta etapa, en las sucesivas experiencias se empleó la relación S/L 1/50.

El efecto de la relación $\mathrm{S} / \mathrm{L}$ ha sido estudiado por varios autores para diferentes materias primas. Una disminución en la relación $\mathrm{S} / \mathrm{L}$, aumenta el rendimiento de la extracción. Es necesario encontrar una relación adecuada entre el solvente y la materia prima a ser extraída. Una proporción alta da lugar a extractos demasiado diluidos y aumenta los costos del posterior secado y si es muy baja no habrá buena difusión [39-42].

\section{Efecto de la temperatura y el tiempo}

En la Figura 2 se presenta la cinética de extracción de pectina a diferentes temperaturas y, en la Figura 3, el rendimiento de MIE a 35 y $40^{\circ} \mathrm{C}$ durante 4 y $6 \mathrm{~h}$ de reacción. 


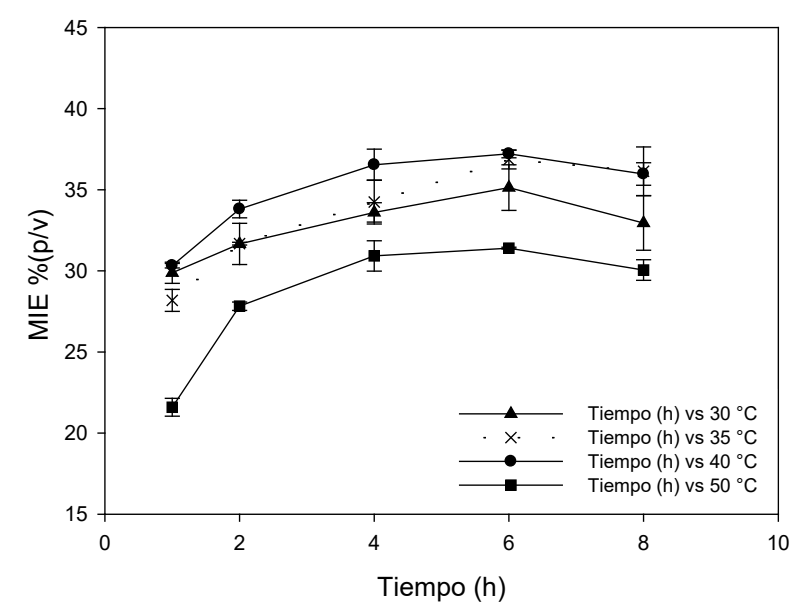

Figura 2: Cinética de extracción de pectina a $30,35,40$ y $50^{\circ} \mathrm{C}$ con el extracto enzimático de Wa cepa 110. Condiciones de extracción: relación $\mathrm{S} / \mathrm{L}:$ 1/50, $25 \mathrm{~mL}$ EE.

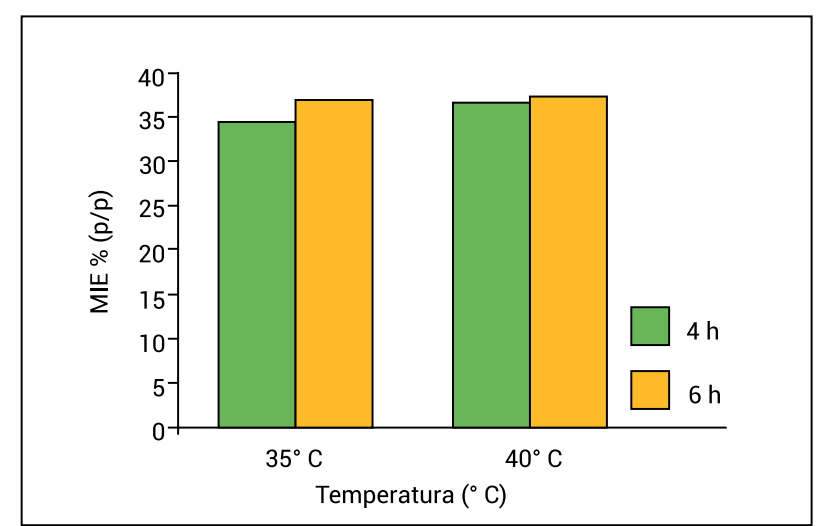

Figura 3: Rendimiento del MIE a 35 y $40^{\circ} \mathrm{C}$ durante 4 y $6 \mathrm{~h}$ de reacción.

Como se observa en la Figura 2 el rendimiento de extracción de pectina aumentó hasta un cierto tiempo, el cual dependió de cada temperatura, y luego permaneció constante. Los rendimientos obtenidos a 35 y $40^{\circ} \mathrm{C}$ fueron superiores a los obtenidos a 30 y $50^{\circ} \mathrm{C}$ a todos los tiempos. A $35^{\circ} \mathrm{C}$, el rendimiento de extracción de pectina alcanzó un valor máximo de $36,86 \pm 0,57 \%(\mathrm{p} / \mathrm{p})$ a las $6 \mathrm{~h}$ de reacción y a $40^{\circ} \mathrm{C}$ de $36,54 \pm 0,96 \%(\mathrm{p} / \mathrm{p})$, a las 4 h (Fig. 3). $\mathrm{El}$ análisis de varianza determinó que no hubo diferencia significativa $(\mathrm{p}<0,05)$ entre los rendimientos de extracción a $35^{\circ} \mathrm{C}-6$ h y $40^{\circ} \mathrm{C}-4 \mathrm{~h}$.

Se obtuvieron blancos de reacción de 9,33 $\pm 0,34 \%(\mathrm{p} / \mathrm{p})$ a 30 y $40^{\circ} \mathrm{C}$, mientras que a $50^{\circ} \mathrm{C}$ fueron de $17,95 \pm 0,39 \%$ $(\mathrm{p} / \mathrm{p})$. Los blancos de la reacción enzimática, mostraron una solubilización de pectina significativa, la cual fue superior a $50^{\circ} \mathrm{C}$. Contreras Esquivel (2003) [43] reportó que la solubilización observada en los blancos, se puede deber a un proceso de extracción química de la pectina, en las condiciones de reacción. Debido a ello, informa que existe un efecto sinérgico en este tipo de procesos, es decir entre la catálisis química (blanco) y la enzimática, siendo superior, en todas las condiciones, el último efecto.

Se han reportado rendimientos de extracción de pectina de albedo de limón por métodos enzimáticos de $27 \mathrm{~g}$ de pectina/100 g de material seco, empleando PGasa de $A$. kawachii y de $17,6 \mathrm{~g}$ de pectina/100 g de material seco con PGasade A. niger [42]. (Zapata Zapata y col. 2009) [2], reportaron rendimientos del 27\% (p/p), utilizando protopectinasa-SE producida por el hongo levaduriforme Geotrichum klebhanii y del 10\% (p/p) para los blancos. (Vasco-Correra y Zapata Zapata 2017) [44], al evaluar la extracción de pectina de maracuyá utilizando una PPasa de G. klebahnii ATCC 42397, informaron rendimientos de extracción de pectina entre $17 \%$ y $25 \%$ (p/p), 8 g/100 g de cáscara seca donde los mayores rendimientos se obtuvieron a $37^{\circ} \mathrm{C}$, mientras que los menores a $44^{\circ} \mathrm{C}$, atribuyéndolo a la inestabilidad de la enzima a esta última temperatura.

Efecto de la actividad enzimática

En la Figura 4 se presentan los rendimientos de pectina (\% MIE) obtenidos con los diferentes volúmenes del EE de Wa cepa 110, manteniendo constante la relación $\mathrm{S} / \mathrm{L}(1 / 50)$, a $40^{\circ} \mathrm{C}$ y $4 \mathrm{~h}$ de incubación.

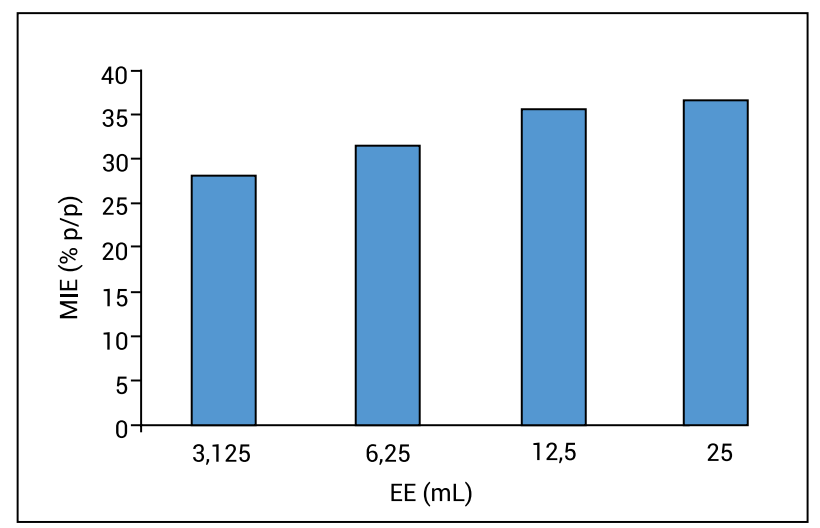

Figura 4: Rendimiento de MIE (\%, p/p) con distintas concentraciones del EE producido por Wa cepa 110. Condiciones de reacción: relación $\mathrm{S} / \mathrm{L} 1 / 50 ; 40^{\circ} \mathrm{C}, 4 \mathrm{~h}$.

El análisis de varianza indicó que el volumen del EE utilizado en el proceso de extracción, influyó significativamente $(\mathrm{p}<0,05)$ en el rendimiento del proceso extractivo. Se obtuvo un aumento en el rendimiento de MIE desde un valor de 28,13 $\pm 0,81 \%(\mathrm{p} / \mathrm{p})$ con 3,125 mL de EE (actividad PGasa en el medio de reacción: 1,22 UE/mL), hasta un valor de $35,9 \pm 0,67 \%(\mathrm{p} / \mathrm{p})$ con $12,5 \mathrm{ml}$ de EE (actividad PGasa en el medio de reacción: 4,28 UE/mL). No hubo diferencia significativa en los valores de rendimiento al utilizar $12,5 \mathrm{~mL}$ o $25 \mathrm{~mL}$ de EE.

\section{Extracción de pectina por el método químico y su caracterización}

En la Tabla 2 se compara el rendimiento de extracción de pectina a partir de albedo de limón, en las condiciones seleccionadas (relación $\mathrm{S} / \mathrm{L} 1 / 50,40^{\circ} \mathrm{C}, 4 \mathrm{~h}, 12,5 \mathrm{~mL} \mathrm{EE}$ ), utilizando PGasa de Wa cepa 110, respecto al rendimiento de extracción obtenido mediante el método químico. 
Tabla 2: Rendimientos de MIE por método químico y enzimático

\begin{tabular}{|c|c|}
\hline Método & MIE\% (p/p) \\
\hline EE de Wa cepa 110 & $35,93 \pm 0,67$ \\
\hline Químico & $24,17 \pm 0,99$ \\
\hline
\end{tabular}

Condiciones de extracción enzimática: relación $\mathrm{S} /$ L1/50; $12,5 \mathrm{~mL}$ del EE, $40^{\circ} \mathrm{C}, 4 \mathrm{~h}$.

El rendimiento de extracción de pectina por el método químico fue de $24,17 \pm 0,99 \%$ (p/p).

Contreras Esquivel (2003) [43] informó rendimientos mediante hidrólisis química del $20,2 \%(\mathrm{p} / \mathrm{p})$, expresado en gramos de pectina extraída por gramo de albedo seco.

Lo anterior indica un aumento de alrededor del $12 \%$ en el rendimiento de extracción de pectina con el EE de Wa cepa 110 respecto al método químico.

La determinación del contenido de AG en el MIE extraído por el método enzimático fue de $413,9 \pm 20,7 \mathrm{mg} / \mathrm{L}$. Teniendo en cuenta que la pectina es un polisacárido que contiene elevado contenido de $\mathrm{AG}$, mediante la extracción enzimática realizada en este estudio el contenido de AG en el MIE resultó ser del $82,57 \%(\mathrm{p} / \mathrm{p})$, indicando que la pectina extraída no contiene cantidades elevadas de impurezas [45].

El GE de la pectina obtenida empleando los extractos de Wa cepa 110, fue de 79,100 $\pm 0,008 \%$ (p/p). Este valor indica que se trata de una pectina de alto metoxilo (HM).

El GE constituye una propiedad química muy importante relacionada con la velocidad de gelificación y solidificación de la pectina. Como se trata de una pectina $\mathrm{HM}$, esto implica que puede ser usada en la formulación de productos como jaleas y mermeladas pero no en productos dietéticos (con bajo agregado de azúcar) [44, 46, 47].

\section{Conclusiones}

El extracto enzimático de Wa cepa 110, fue capaz de extraer pectina de citrus a partir de albedo de limón, a temperaturas y tiempos moderados. El rendimiento del material insoluble en etanol (MIE) obtenido fue de $35,93 \pm 0,67 \%(\mathrm{p} / \mathrm{p})$, con una relación $\mathrm{S} / \mathrm{L}$ de $1 / 50,40^{\circ} \mathrm{C}, 4$ $\mathrm{h}$ de incubación y $12,5 \mathrm{~mL}$ de EE (actividad PGasa en el medio de reacción: 4,28 UE/mL). Este valor fue superior al obtenido utilizando el método químico, lo cual confirma la bondad del proceso enzimático utilizado. La pectina extraída presentó un GE de 79,100 $\pm 0,008 \%$ (p/p), lo que indica que se trata de una pectina de alto metoxilo (HM).

La extracción de pectina por vía enzimática constituye una tecnología innovadora, alternativa al método tradicional de extracción por vía química, con las ventajas operativas y económicas que ello representa y en condiciones amigables con el medio ambiente.

\section{Agradecimientos}

Esta investigación fue parcialmente respaldada por la Secretaría de Políticas Universitarias (SPU) y la Facultad de Ciencias Exactas, Químicas y Naturales de la Misiones Nacionales de la Universidad. La Ing. Silvana A. Maidana posee una Beca Interna Doctoral, otorgada por el Consejo Nacional de Investigaciones Científicas y Técnicas (CONICET). Los autores desean agradecer a la Ing. Vanesa P. Esteche y a la estudiante Valeria Fernández Müller, ambas becarias del Comité Ejecutivo de Desarrollo e Innovación Tecnológica (CEDIT- Misiones), por haber colaborado en el desarrollo de los procesos fermentativos.

\section{Referencias}

1. Baciu, J.; Jördening H. Kinetics of galacturonic acid relese from sugar beet pulp, Enzyme and Microbial Technology. 34: p. 505-512. 2005.

2. Zapata Zapata, A.D; Escobar, C.; Cavalitto, S.F.; Hours, R.A. Evaluación de la capacidad de solubilización de pectina de cáscara de limón usando protopectinasa-SE. Revista de la Facultad de Química Farmacéutica. 16: p. 67-74. 2009.

3. International Trade Center. Product country graph. 2016. [Online]. http://www.trademap.org/. (Consulta: 28 Nov. 2018).

4. May, C. D., Industrial pectins: sources, production and applications, Carbohydr. Polym. 12: p.79-99. 1990.

5. Liew, S. Q.; Chin, N. L.; Yusof, Y. A.; Sowndhararajan, K. Comparison of acidic and enzymatic pectin extraction from passion fruit peels and its gel properties, J. Food Process Eng. 39: p. 501-511. 2016.

6. Contreras-Esquivel, J. C.; Hours, R. A.; Aguilar, C. N.; Reyes-Vega, M. L.; Romero, J. Microbial and enzymatic extraction of pectin: a review, Archivos Latinoamericanos de Nutricion. 47: p. 208-216. 1997.

7. Schroder, R.; Christopher, J.C.; Sharrock, K.; Hallett, I.C.; MacRae, E.A. Pectins from the albedo of immature lemon fruitless have high water binding capacity, J Plant Physiol. 161 (4): p. 371-379. 2004.

8. Cavalitto, S. F., \& Mignone, C. F. Application of factorial and Doehlert designs for optimization of protopectinase production by a Geotrichum klebahnii strain, Process Biochem. 42: p. 175-179. 2007.

9. Sakamoto, T.; Hours, R.A., Sakai, T. Enzymatic pectin extraction from protopectins using microbial protopectinasas, Process Biochem. 30 (5): p. 403-409. 1995

10. Cavalitto, S.F.; Hours, R.A.; Mignone, C.F. Growth and protopectinase production of Geotrichum klebahnii in batch and continuous cultures with synthetic media, J. Ind. Microbiol. Biotechnol. 25: p. 260-265. 2000.

11. Kim, D.H.; Kim, D.G.; Lee, D.Y.; Kim, K.E.; Kim, C.W. Physicochemical characterization of pectin extracted from cheju 
mandarin (Citrus unshiu) peels with citric acid, Food Sci Biotech. 9 (2): p. 95-98. 2000.

12. Jayani, R.S.; Saxena, S.; Grupta, R. Microbial Pectinolytic Enzymes, Process Biochem. 40: p. 2931-2944. 2005.

13. Tari, C.; Gögus, N.; Tokatli, F. Optimization of biomass, pellet size and polygalacturonase production by Aspergillus sojae ATCC 20235 using response surface methodology, Enzyme and Microbial Technology. 40 (5): p.11081116. 2007.

14. Contreras-Esquivel, J. C.; Aguilar, C. N.; Montanez, J. C., Brandelli, A.; Espinoza-Perez, J.D.; Renard, C. M. G. C. Pectin from passion fruit fiber and its modification by pectinmethylesterase, J. Food Science and Nutrition. 15: p. 57-66. 2010.

15. Franchi, M.L.; Marzialetti, M.B.; Pose, G.N.; Cavalitto, S.F., Evaluation of enzymatic pectin extraction by a recombinant polygalacturonase (PGI) from apples and pears pomace of argentinean production and characterization of the extracted pectin. J. Food Process Technol. 5 (8): p. 1-4. 2014.

16. Cavalitto, S. F.; Hours, R. A.; Mignone, C. F. Quantification of protopectinase-SE, an endopolygalacturonase with pectin-releasing activity from Geotrichum klebahnii, Biotechnol. Techniques. 13: p. 385-390. 1999.

17. Martos, M.A.; Zubreski, E.R.; Garro, O.A.; Hours, R.A. Production of pectinolytic enzymes by the yeast Wickerhanomyces anomalus isolated from citrus fruits Peels, Biotechnol. Res.Int. p. 1-7. 2013 b.

18. Martos, M. A.; Butiuk, A.P.; Rojas, N.L.; Hours, R.A. Purification and characterization of a polygalacturonase produced by Wickerhamomyces anomalus, Braz. Arch. Biol. Technol. 57(4): p. 587-594. 2014b.

19. Zubreski, E.R., Ms.Sc. Thesis: Aislamiento de Wickerhamomyces anomalus una levadura productora de poligalacturonasa con capacidad macernate de tejidos vegetales. Facultad de Ciencias Exactas Químicas y Naturales, Universidad Nacional de Misiones. 2013.

20. Martos, M.A.; Zubreski, E.R.; Combina, M.; Garro, O.A.; Hours, R.A. Isolation of a yeast strain able to produce a polygalacturonase with maceration activity of cassava roots, Food Sci.Technol. 33(2): p. 332-338. 2013 a.

21. Martos, M.A.; Butiuk, A.P.; Rojas, N.L.; Hours, R.A. Batch culture of Wickerhamomyces anomalus in a lab scale bioreactor for poligalacturonase production, Rev. Colomb. Biotecnol. 16(2): p. 68-73. 2014a.

22. Herbert, D.; Phipps, P.J., Strange, R.E. Chapter III Chemical Analysis of Microbial Cells. Methods in Microbiology, 5:p. 209-344. 1971.

23. Ferreyra, O.A.; Cavalitto, S.F.; Hours, R.A.; Ertola, R.J. Influence of trace elements on enzyme production: protopectinase expression by a Geotrichum klebahnii strain. Enzyme Microb. Technol. 31(4):p. 498-504. 2002.

24. Soares Junior, M.S.; Reis, R.C.; Bassinello, P.Z.; Lacerda, D.B.C.; Koakuzu, S.N.; Caliari, M. Qualidade de biscoitos formulados com diferentes teores de farinha de casca de pequi, Pesquisa Agropecuária Tropical. 39 (2): p. 98104. 2009.
25. Contreras-Esquivel, J.C.; Hours, RA.; Voget, C.E.; Mignone, CF. Aspergillus kawachii produces an acidic pectin releasing enzyme activity, J. Biosci. Bioeng. 88: p. 48-52. 1999.

26. Munhoz, C.L.; Sanjinez-Argandona, E.J.; Soares-Junior, M. S. Extração de pectina de goiaba desidratada, Ciência e Tecnologia de Alimentos. 30: p. 119-125. 2010.

27. Dos Santos Siqueira, B.; Dias Alves, L.; Vasconcelos, N.; Damiani, P.; Soares, J. M. Pectina extraída de casca de pequi e aplicação em geléia light de manga, Rev. Bras. Frutic. 34 (2): p. 560-567. 2012.

28. Canteri, M.H.G.; Moreno, L.; Wosiacki, G.; Scheer, A. Pectina: da-Matéria ao Produto Final, Polímeros. 22 (2): p. 149-157. 2012.

29. Rehman, HU, Qader, SAU, Aman, A, 2012. Polygalacturonase: production of pectin depolymerising enzyme from $\mathrm{Ba}$ cillus licheniformis KIBGE IB-21. Carbohydr. Polym. 90 (1), 387-391.

30. Embaby, A. M.; Masoud, A. A.; Marey, H.S.; Shaban N.Z.; Ghonaim, T.M. Raw agro-industrial orange peel waste as a low cost effective inducer for alkaline polygalacturonase production from Bacillus licheniformis SHG10. SpringerPlus. 3: p. 327. 2014.

31. Stat Graphics. Centurión $X V$, Statpoint Technologies, Inc., Warrenton, VA, USA, 2009.

32. Royo-Iranzo, J.; Miralles, M.C.; Claramunt, P. Preparación de corteza de naranja para la obtención de pectina a partir de dos variedades cultivadas en España. Rendimiento y calidad del producto. Agroquímica Tecnología de Alimentos. 15: p. 539-546. 1975.

33. Normah, 0.; Ku Hasnah, K. A. Pectin content of selected local fruit by-products(Kandungan pektin dalam hasilan sampingan buah-buahan tempatan terpilih) J. Trop. Agric. and Fd. Sc. 28(2):p. 195-201. 2000.

34. Rojas, N.L.; Cavalitto, S.F.; Mignone, C.F.; Hours, R.A. Role of PPase-SE in Geotrichum klebahnii, a yeast-like fungus able to solubilize pectin. Electron. J. Biotechnol. 11 (1):p. 1-8. 2008.

35. Melton, L.D.; Smith, B.G. Determination of the uronic acid content of plant cells walls using a colorimetric assay. Current Protocols in Food Analytical Chemestry: E3.3.1-E3.3.4. 2001.

36. Food Chemicals Codex. FCc. Revised Monograph-Pectins. Estados Unidos. 1996. Disponible en: books.nap.edu/ $\mathrm{html} / \mathrm{fcc} /$ pectins.pdf.

37. Singthong, J.; Cui, S.W.; Ningsanond, S.; Goff, H.D. Structural Characterization, degree of esterification y some gelling properties of Krueo Ma Noy (Cissampelos pareira) pectin, Carbohydr. Polym. 58 (4): p. 391-400. 2004.

38. Sit, N.; Agrawal, U.S.; Deka, S.C. Effect of enzyme concentration, addition of water and incubation time on increase in yield of starch from potato, J. Food Sci. Technol. 51(5): p. 1011-1015. 2014.

39. Cacace, J.E.; Mazza G. Optimization of extraction of antho- 
cyanins from black currants with aqueous etanol, J. Food Sci. 68(1): p. 240-248. 2003.

40. Herodez, S. S.; Hadolin, M.; Skerget, M.; Knez, z. Solvent extraction study of antioxidants from Balm (Melissa officinalis L.) leaves, Food Chem. 80 (2). p. 275-282. 2003.

41. Pinelo, M.; Del Fabbro, P.; Marzocco, L.; Nuñez, M. J.; Vicoli, M. C. Optimization of continuous phenol extraction from Vitis vinifera byproducts, Food Chem. 92: p. 109-117. 2005.

42. Spigno, G.; Tramelli, L.; De Faveri, D.M. Effects of extraction time, temperature and solvent on concentration and antioxidant activity of grape marc phenolics, J. Food Eng. 81: p. 200-208. 2007.

43. Contreras Esquivel, J.c. Tesis Doctoral: Purificación y caracterización de poligalacturonasas de Aspergillus kawachii, Facultad de Ciencias Exactas, Universidad Nacional de La Plata. 2003.
44. Vasco-Correa, J.; Zapata Zapata, A.D. Enzymatic extraction of pectin from passion fruit peel (Passiflora edulis $f$. flavicarpa) at laboratory and bench scale, LWT - Food Sci. Technol. 80: p.280-285. 2017.

45. Guidi, A.; Quiroga, M. Obtención de pectina a partir de la cáscara de maracuyá mediante hidrólisis, JBC. 7 (21): p. 67-71. 2010.

46. Sinclair, W.B. and Crandall, P.R. Carbohydrate fractions of lemon peel, Plant Physiol. 601: p. 681-705. 2008.

47. Malgorzata, D.; Søndergaard, K. M.; Wichmann, J.; Vidal-Melgosa, S.; Willats, W. G.T.; Meyer, A. S.; Mikkelsen, J. D. Application of enzymes for efficient extraction, modification, and development of functional properties of lime pectin, Food Hydrocolloids. 40: p. 274-282. 2014.

Recibido: 17/09/2018.

Aprobado: 04/06/2019. 